\title{
Correction to: Combining GSN and STPA for Safety Arguments
}

\author{
Celso Hirata (iD) and Simin Nadjm-Tehrani (D)
}

\section{Correction to:}

\section{Chapter "Combining GSN and STPA for Safety Arguments" in: A. Romanovsky et al. (Eds.): Computer Safety, Reliability, and Security, LNCS 11699, https://doi.org/10.1007/978-3-030-26250-1_1}

In the originally published version of this chapter there was an error in figure 2. This has been corrected.

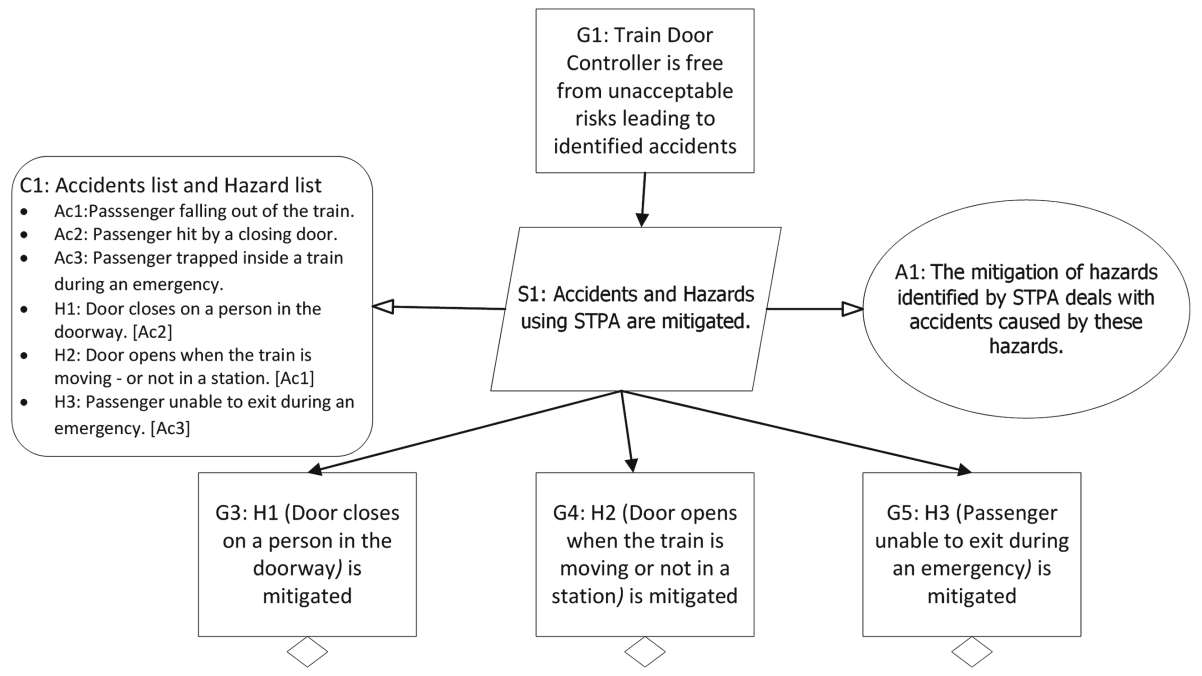

The updated version of this chapter can be found at https://doi.org/10.1007/978-3-030-26250-1_1 